\title{
NOTES
}

\section{Ehrlichia ewingii sp. nov., the Etiologic Agent of Canine Granulocytic Ehrlichiosis}

\author{
BURT E. ANDERSON,${ }^{1 *}$ CRAIG E. GREENE, ${ }^{2}$ DANA C. JONES,${ }^{1}$ AND JACQUELINE E. DAWSON ${ }^{1}$ \\ Viral and Rickettsial Zoonoses Branch, Division of Viral and Rickettsial Diseases, National Center for Infectious \\ Diseases, Centers for Disease Control, Atlanta, Georgia $30333,{ }^{1}$ and Department of Small Animal Medicine, \\ College of Veterinary Medicine, University of Georgia, Athens, Georgia $30602^{2}$
}

\begin{abstract}
The 16S rRNA gene was amplified, cloned, and sequenced from the blood of two dogs that were experimentally infected with the etiologic agent of canine granulocytic ehrlichiosis. The 16S rRNA sequence was found to be unique when it was compared with the sequences of other members of the genus Ehrlichia. The most closely related species were Ehrlichia canis (98.0\% related) and the human ehrlichiosis agent (Ehrlichia chaffeensis) (98.1\% related); all other species in the genus were found to be phylogenetically much more distant. Our results, coupled with previous serologic data, provide conclusive evidence that the canine granulocytic ehrlichiosis agent is a new species of the genus Ehrlichia that is related to, but is distinct from, $E$. canis and all other members of the genus. We propose the name Ehrlichia ewingii sp. nov.; the Stillwater strain is the type strain.
\end{abstract}

Ehrlichia canis, the type species of the genus Ehrlichia, was first described by Donatien and Lestoquard in 1935 (7). The first case of canine ehrlichiosis in the United States was described by Ewing in 1963 and was complicated by a concurrent Babesia canis infection (8). Although the clinical manifestations of canine ehrlichiosis depend in part on the breed of dog, the illness is considered severe (11). One of the characteristic features of acute canine ehrlichiosis is the presence of Ehrlichia canis in lymphocytes and monocytes. In 1971, Ewing et al. described a new strain of Ehrlichia canis that was found in granulocytes (primarily neutrophils) and produced a mild form of canine ehrlichiosis (10). This organism has subsequently been referred to as the canine granulocytic Ehrlichia (CGE), and the corresponding disease is called canine granulocytic ehrlichiosis (16). Electron microscopy has revealed that the CGE is found in infected cells as inclusions (termed morulae) that are characteristic of the genus Ehrlichia (8a). The morulae consist of small numbers of pleomorphic individual cells surrounded by a host cell membrane. Serologic cross-reactivity between the CGE and Ehrlichia canis has been demonstrated, but the two organisms can be distinguished from each other and from Ehrlichia equi by the results of quantitative immunofluorescent assays (9). In addition, an enzyme-linked immunosorbent assay and an immunoblot analysis have shown that the CGE and Ehrlichia canis are readily differentiated (14). We amplified, cloned, and sequenced the 16S rRNA gene from the blood of two dogs that were infected with the CGE and compared the resulting $16 \mathrm{~S}$ rRNA sequence with the sequences obtained previously for all other currently recognized species in the genus Ehrlichia (1). We also compared the sequence obtained from CGE-infected dog blood with the sequence of "Ehrlichia platys," an Ehrlichia sp. that is known to infect platelets in dogs (15). The taxonomic relationship between the CGE and the other ehrlichiae, including the recently proposed species thought to be the agent of

\footnotetext{
* Corresponding author.
}

human ehrlichiosis (Ehrlichia chaffeensis) (1) is discussed below.

The passage history of the CGE used in this study is described below. A field case of canine granulocytic ehrlichiosis was diagnosed at Boren Veterinary Medical Teaching Hospital, Oklahoma State University, Stillwater, on 18 June 1987. Whole blood from this dog was transfused into a susceptible dog, and three additional passages were performed in an identical fashion. In 1988 and 1989 two successive passages were made via tick feeding (2). Specifically, Amblyomma americanum nymphs were exposed to infected dogs, and the resulting adult ticks transmitted the agent to susceptible dogs. Blood from one of these dogs was used for two subsequent independent passages via blood transfusion at two different locations. The first passage line occurred at Oklahoma State University with two dog-to-dog passages. Blood from the second dog that was infected was collected in the presence of EDTA and used as a source of template DNA in the polymerase chain reaction (PCR). The second, independent passage line occurred at the University of Georgia with three successive dog-to-dog transmissions; blood from the third dog that was infected was used as an additional source of template DNA for the PCR.

Blood specimens from a dog infected with "Ehrlichia platys" were kindly provided by Richard Corstvet, Louisiana State University, Baton Rouge. DNA was extracted from each of the blood samples and PCR amplified as previously described (17). Briefly, two pairs of universal primers that are known to amplify more than $90 \%$ of the bacterial 16S rRNA gene as two separate products (21) were used together with a third more specific pair of primers (1) to prime amplification. The DNA extracted from the CGEinfected dog blood was amplified for three cycles consisting of $94^{\circ} \mathrm{C}$ for $1 \mathrm{~min}, 48^{\circ} \mathrm{C}$ for $2 \mathrm{~min}$, and $66^{\circ} \mathrm{C}$ for $1.5 \mathrm{~min}$; this was followed by amplification for 37 cycles consisting of $88^{\circ} \mathrm{C}$ for $1 \mathrm{~min}, 52^{\circ} \mathrm{C}$ for $2 \mathrm{~min}$, and $68^{\circ} \mathrm{C}$ for $1.5 \mathrm{~min}$. The 733-bp PCR product which was obtained when universal primers EC9 and EC10 were used to amplify DNA extracted 


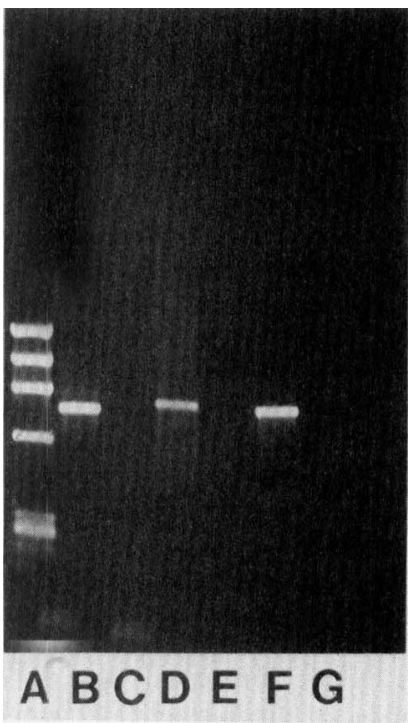

FIG. 1. Agarose (1\%) gel of PCR products obtained after amplification of DNA extracted from Ehrlichia ewingii-infected dog blood (lanes B, D, and F) or no DNA control (lanes C, E, and G). The following primers were used for amplification: lanes B and C, EC9 and EC10; lanes D and E, EC11 and EC12; lanes F and G, EC19 and EC20. Lane A contained $\phi X 174$ phage DNA cleaved with HaeIII, which provided molecular size standards $(1,378,1,078,872,603$, $310,281 / 271,234,194,118$, and $72 \mathrm{bp}$ )

from CGE-infected dog blood (Fig. 1, lane B), corresponded to the 3 ' one-half of the 16S rRNA gene. Likewise, universal primers EC11 and EC12 defined a 767-bp PCR fragment that corresponded to the $5^{\prime}$ one-half of the $16 \mathrm{~S}$ rRNA from CGE (Fig. 1, lane D). Specific primers EC19 and EC20 defined a 757-bp product when they were used to amplify the DNA template from CGE-infected dog blood (Fig. 1, lane F). All of the primers contained unique restriction sites to allow cloning of the resulting PCR products. The PCR products were gel purified and cloned into pUC19. After transformation into Escherichia coli DH5alpha, colonies were screened for the correct size of insertion, and the double-stranded DNA was sequenced with T7 DNA polymerase (Sequenase; U.S. Biochemicals, Cleveland, Ohio). Each PCR product was amplified independently, cloned, and sequenced at least twice to prevent the reading of PCR incorporation errors. In fact, the cloned PCR product obtained with primers EC9 and EC10 for the Oklahoma source of CGE-infected dog blood disagreed at two nucleotide positions between the first and second determinations. A third, independent amplification, cloning, and sequencing procedure resolved this discrepancy because the resulting sequence agreed completely with one of the two sequences determined previously. Nucleotide sequences were assembled from the PCR products. The final sequences (consisting of more than 1,400 nucleotides) for the Oklahoma and Georgia sources of the PCR template agreed completely and were aligned, for maximal homology, over the entire 16S rRNA gene with the sequences from other Ehrlichia strains by using the gap program of the genetics computer group package (6).

The results of pairwise alignments of the CGE $16 \mathrm{~S}$ rRNA gene sequence and the sequences reported for all other members of the genus Ehrlichia (1) are shown in Table 1. The phylogenetically most closely related species is Ehrlichia chaffeensis (98.1\%), the recently described agent that
TABLE 1. 16S rDNA relatedness between Ehrlichia ewingii and other Ehrlichia species

\begin{tabular}{|c|c|}
\hline Species and/or strain & $\begin{array}{l}\text { \% Relatedness to } \\
\text { Ehrlichia ewingii }\end{array}$ \\
\hline Ehrlichia chaffeensis Arkansas ${ }^{a}$. & 98.1 \\
\hline Ehrlichia canis Florida ${ }^{a} . . . . . . . . . .$. & 98.0 \\
\hline Ehrlichia equi ${ }^{a} \ldots . . . . . . . . . . .$. & 92.4 \\
\hline Ehrlichia phagocytophila $\mathrm{OS}^{a}$. & 92.4 \\
\hline "Ehrlichia platys"............... & 91.7 \\
\hline Ehrlichia sennetsu Miyayama ${ }^{a}$. & 84.5 \\
\hline Ehrlichia risticii Illinois $^{b}$.. & 83.9 \\
\hline
\end{tabular}

${ }^{a}$ The strain sources and 16S rRNA sequences have been described previously (1).

${ }^{b}$ Data from reference 20

was isolated from a patient with human ehrlichiosis (1). Ehrlichia canis is slightly less closely related (98.0\%) to the CGE than Ehrlichia chaffeensis is. We observed greater 16S rRNA sequence divergence between the CGE and its closest relative, Ehrlichia chaffeensis ( $1.9 \%$ divergence), than has been reported previously for two other currently recognized species within the genus, Ehrlichia risticii and Ehrlichia sennetsu (1.0\% divergence) (1). The CGE falls into a group within the genus Ehrlichia that consists of Ehrlichia canis (type species) and Ehrlichia chaffeensis. This group of three species is phylogenetically very distant from the Ehrlichia risticii-Ehrlichia sennetsu group (1) and somewhat more closely related to the Ehrlichia phagocytophila-Ehrlichia equi group (1). The 16S rRNA gene sequence of "Ehrlichia platys" is most closely related to the Ehrlichia phagocytophila-Ehrlichia equi group sequences and is clearly distinct from the sequence of the CGE. The 16S rRNA gene sequencing results provide genetic evidence that the CGE is a unique member of the genus Ehrlichia which deserves species level recognition.

The International Committee on Systematic Bacteriology Ad Hoc Committee on Reconciliation of Approaches to Bacterial Systematics has recommended that "the phylogenetic definition of a species generally would include strains with approximately $70 \%$ or greater DNA-DNA relatedness and with $5^{\circ} \mathrm{C}$ or less $T_{m}$ "(18). Ideally, species descriptions should include both phenotypic data and phylogenetic analysis (12). The application of such a definition to members of the genus Ehrlichia is impossible, given that several species are uncultivatable and all species are extremely difficult to purify away from host cell debris, preventing accurate DNA-DNA relatedness determinations. Consequently, alternative taxonomic criteria must be used to classify members of the genus Ehrlichia. The use of macromolecular semantides for the purposes of taxonomy has recently gained popularity. In particular, 16S rRNA has been the macromolecule that has been used most frequently (12). Sequencing of 16S rRNA is especially useful when coupled with PCR amplification. In this fashion, 16S rRNA sequences can be obtained for both cultured Ehrlichia species and species isolated from the blood of infected animal hosts. This approach allows sequence comparisons of all members of the genus Ehrlichia in which the same criteria are used. Recently, PCR amplification of the 16S rRNA gene followed by sequencing has been used to identify or characterize other members of the order Rickettsiales, to which the genus Ehrlichia belongs $(1,13,19)$.

Additional phenotypic evidence of differences between the CGE and other members of the genus Ehrlichia has been reported previously $(9,14,16)$. The CGE differs from 


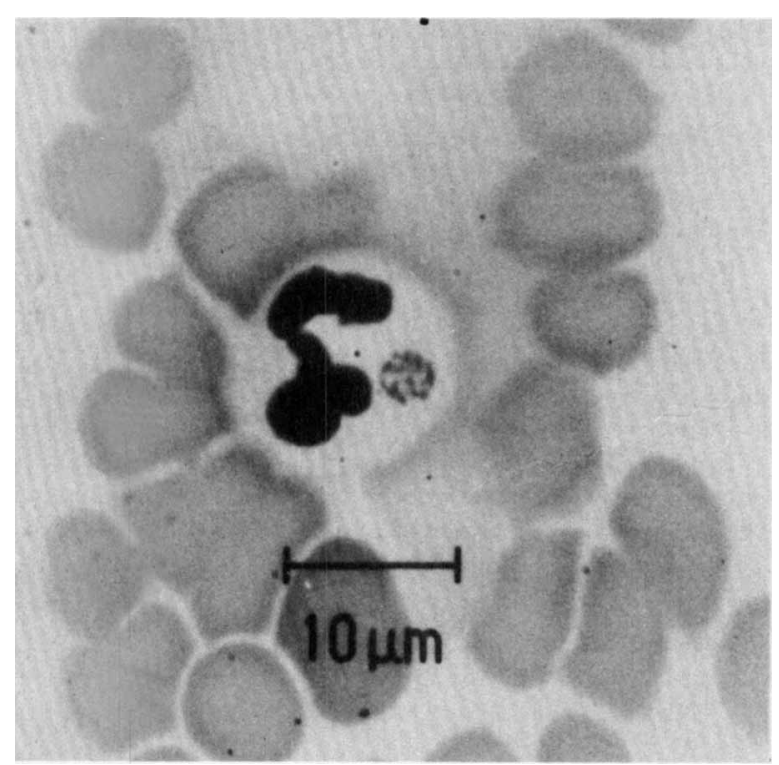

FIG. 2. Photomicrograph showing dog neutrophil containing morula of Ehrlichia ewingii sp. nov.

Ehrlichia canis in that it exhibits a preference for granulocytes instead of mononuclear cells as the host cells that are most frequently infected (Fig. 2). The initial (acute-phase) disease produced by the CGE in dogs appears to be milder than classic canine ehrlichiosis caused by Ehrlichia canis, and the chronic phase also differs in nature $(2-5,10)$. Specifically, transient fever, oculonasal discharges, lymphadenomegaly, and thrombocytopenia are manifestations that are observed with acute CGE infections. With acute Ehrlichia canis infections, the same abnormalities are usually observed but are more severe, and the hematologic finding is pancytopenia. Peripheral edema, lymphadenomegaly, and suppurative polyarthritis are the most consistent clinical findings with chronic CGE infections. Abnormal findings of leukocytosis, lymphopenia, and thrombocytopenia are variable. In contrast, chronic Ehrlichia canis infections are characterized by debilitation, lymphadenomegaly, fever, hemorrhagic diathesis, and signs referred to as meningoencephalomyelitis. Associated abnormal findings include pancytopenia, hyperglobulinemia, bone marrow hypoplasia, and plasmacytosis of many tissues, most commonly involving the lungs, brain, meninges, kidneys, lymph nodes, and spleen. Serologic data have also shown that the CGE is antigenically related but distinct from other ehrlichiae ( 9 , 14). Thus, the phenotypic observations coupled with the unique 16S rRNA gene sequence provide compelling evidence that a separate species is warranted for the CGE.

Previous attempts by workers in our laboratory to cultivate CGE in various cell lines has failed. Among the cell lines which have been used are cell lines DH82 (a continuous canine macrophage cell line), HL-60 (a human promyelocytic leukemia cell line), CLN (a continuous canine lymph node cell line), and primary canine monocytes. Two of these cell types, cell lines DH82 and primary canine monocytes, have been used successfully to cultivate Ehrlichia canis in vitro. Thus, the CGE and other granulocytic ehrlichiae may be difficult or impossible to cultivate in vitro.

Description of Ehrlichia ewingii sp. nov. Ehrlichia ewingii (ew.in'gi.i. N.L. gen. n. ewingii, in honor of Sidney A. Ewing for his pioneering work with this agent). Exhibits all of the characteristics of the genus Ehrlichia (i.e., cytoplasmic growth that appears as compact clusters of organisms termed morulae [Fig. 2] and serologic cross-reactivity with Ehrlichia canis). Ehrlichia ewingii is distinct from Ehrlichia canis in that it is found primarily in granulocytes and seems to cause a milder form of acute canine ehrlichiosis and to result in a chronic phase that differs from classic canine ehrlichiosis. Ehrlichia ewingii and Ehrlichia canis are also serologically distinct. Ehrlichia ewingii can be differentiated from all other members of the genus by its unique 16S rRNA gene sequence. The type species is the Stillwater strain of Ehrlichia ewingii, which was originally obtained from the blood of a naturally infected dog. Attempts to cultivate Ehrlichia ewingii in tissue culture have been unsuccessful.

Nucleotide sequence accession numbers. The GenBank accession number for the 16S rRNA gene of the CGE (Ehrlichia ewingii) is M73227, and the accession number for the "Ehrlichia platys" 16S rRNA gene is M82801.

We thank the following individuals: James Olson for reviewing the manuscript; Thomas MacAdoo, Virginia Polytechnic Institute and University, Blacksburg, for advice on naming the canine granulocytic ehrlichiosis agent; Sidney A. Ewing, Oklahoma State University, for providing CGE-infected dog blood specimens and for providing the photomicrograph in Fig. 2; and Richard Corstvet, Louisiana State University, for providing the "Ehrlichia platys"infected dog blood specimens.

\section{REFERENCES}

1. Anderson, B. E., J. E. Dawson, D. C. Jones, and K. H. Wilson. 1991. Ehrlichia chaffeensis, a new species associated with human ehrlichiosis. J. Clin. Microbiol. 29:2838-2842.

2. Anziani, D. S., S. A. Ewing, and R. W. Barker. 1990. Experimental transmission of a granulocytic form of the tribe Ehrlichieae by Dermacentor variabilis and Amblyomma americanum to dogs. Am. J. Vet. Res. 51:929-931.

3. Bellah, J. R., R. M. Shull, and E. V. Shull Selcer. 1986. Ehrlichia canis-related polyarthritis in a dog. J. Am. Vet. Med. Assoc. 189:922-923.

4. Carillo, J. M., and R. A. Greene. 1978. A case report of canine ehrlichiosis: neutrophilic strain. J. Am. Anim. Hosp. Assoc. 14:100-104.

5. Cowell, R. L., R. D. Tyler, K. D. Clinkenbeard, and J. H. Meinkoth. 1988. Ehrlichiosis and polyarthritis in three dogs. J. Am. Vet. Med. Assoc. 192:1093-1095.

6. Devereux, J., P. Haeberli, and O. Smithies. 1984. A comprehensive set of sequence analysis programs for the VAX. Nucleic Acids Res. 12:387-395.

7. Donatien, A., and F. Lestoquard. 1935. Existence en Algerie d'une Rickettsia du chien. Bull. Soc. Pathol. Exot. 28:418-419.

8. Ewing, S. A. 1963. Observations on leukocytic inclusion bodies from dogs infected with Babesia canis. J. Am. Vet. Med. Assoc. 143:503-506.

8a.Ewing, S. A. Personal communication.

9. Ewing, S. A., J. C. Fox, E. M. Johnson, C. G. MacAllister, R. E. Corstvet, C. J. Baldwin, D. A. Mosier, K. M. Kocan, R. D. Tyler, and R. L. Cowell. 1988. Canine ehrlichiosis: differences between granulocytic and agranulocytic agents, abstr. 221. 69th Annu. Meet. Conf. Res. Work. Anim. Dis.

10. Ewing, S. A., W. R. Roberson, R. G. Buckner, and C. S. Hayat. 1971. A new strain of Ehrlichia canis. J. Am. Vet. Med. Assoc. 159:1771-1774.

11. Huxsoll, D. L., P. K. Hildebrandt, R. M. Nims, and J. S. Walker. 1970. Tropical canine pancytopenia. J. Am. Vet. Med. Assoc. 157:1627-1632.

12. Murray, R. G. E., D. J. Brenner, R. R. Colwell, P. De Vos, M. Goodfellow, P. A. D. Grimont, N. Pfennig, E. Stackebrandt, and G. A. Zavarzin. 1990. Report of the Ad Hoc Committee on Approaches to Taxonomy within the Proteobacteria. Int. J. Syst. Bacteriol. 40:213-215.

13. Relman, D. A., J. S. Loutit, T. M. Schmidt, S. Falkow, and L. S. 
Tompkins. 1990. The agent of bacillary angiomatosis. N. Engl. J. Med. 323:1575-1580.

14. Rikihisa, Y., S. A. Ewing, J. C. Fox, A. G. Siregar, F. H. Pasaribu, and M. B. Malole. 1992. Enzyme-linked immunosorbent assay and Western immunoblot analysis of Ehrlichia canis and a canine granulocytic Ehrlichia infection. J. Clin. Microbiol. 30:143-148.

15. Ristic, M., and D. L. Hoxsoll. 1984. Ehrlichieae, p. 704-709. In N. R. Krieg and J. G. Holt (ed.), Bergey's manual of systematic bacteriology, vol. 1. The Williams \& Wilkins Co., Baltimore.

16. Stockham, S. L., D. A. Schmidt, and J. W. Tyler. 1985. Canine granulocytic ehrlichiosis in dogs from central Missouri: a possible cause of polyarthritis. Vet. Med. Rev. 6:3-5.

17. Tzianabos, T., B. E. Anderson, and J. E. McDade. 1989. Detection of Rickettsia rickettsii DNA in clinical specimens by using polymerase chain reaction technology. J. Clin. Microbiol. 27:2866-2868.
18. Wayne, L. G., D. J. Brenner, R. R. Colwell, P. A. D. Grimont, O. Kandler, M. I. Krichevsky, L. H. Moore, W. E. C. Moore, R. G. E. Murray, E. Stackebrandt, M. P. Starr, and H. G. Truper. 1987. Report of the Ad Hoc Committee on Reconciliation of Approaches to Bacterial Systematics. Int. J. Syst. Bacteriol. 37:463-464.

19. Weisburg, W. G., S. M. Barnes, D. A. Pelletier, and D. J. Lane. 1991. 16S ribosomal DNA amplification for phylogenetic study. J. Bacteriol. 173:697-703.

20. Weisburg, W. G., M. E. Dobson, J. E. Samuel, G. A. Dasch, L. P. Mallavia, O. Baca, L. Mandelco, J. E. Sechrest, E. Weiss, and C. R. Woese. 1989. Phylogenetic diversity of the rickettsiae. J. Bacteriol. 171:4202-4206.

21. Wilson, K. H., R. B. Blitchington, and R. C. Greene. 1990. Amplification of bacterial 16S ribosomal DNA with polymerase chain reaction. J. Clin. Microbiol. 28:1942-1946. 